\title{
The IncRNA ANRIL Gene rs2 I5 I280 GG Genotype is Associated with Increased Susceptibility to Recurrent Miscarriage in a Southern Chinese Population
}

\author{
Di Che ${ }^{1, *}$ \\ Zhenzhen Fang ${ }^{2, *}$ \\ Hanran Mai',* \\ Yufen $X u^{\prime}$ \\ LanYan Fu' \\ Huazhong Zhou' \\ Linyuan Zhang' \\ Lei $\mathrm{Pi}^{1}$ \\ Xiaoqiong $\mathrm{Gu}^{\prime}$ \\ 'Department of Clinical Biological \\ Resource Bank, Guangzhou Institute of \\ Pediatrics, Guangzhou Women and \\ Children's Medical Center, Guangzhou \\ Medical University, Guangzhou, People's \\ Republic of China; ${ }^{2}$ Program of Molecular \\ Medicine, Guangzhou Women and \\ Children's Hospital, Zhongshan School of \\ Medicine, Sun Yat-sen University, \\ Guangzhou, People's Republic of China
}

*These authors contributed equally to this work
Background: Genetic factors may play an important role in susceptibility to recurrent miscarriage. Some cardiovascular disease-related candidate genes have been shown to be associated with recurrent miscarriage. Long noncoding RNA ANRIL has been confirmed to be associated with susceptibility to various diseases, such as cardiovascular disease. However, it remains unclear whether the ANRIL gene polymorphism is related to recurrent miscarriage susceptibility.

Methods: Three ANRIL gene polymorphisms (rs2151280, rs1063192 and rs564398) were genotyped in 819 controls and 610 recurrent miscarriage patients through TaqMan real-time polymerase chain reaction. The odds ratios and $95 \%$ confidence intervals (CIs) were used to assess the strength of each association.

Results: Our results showed that the ANRIL rs2151280 GG genotype was associated with increased susceptibility to recurrent miscarriage (GG vs AA: adjusted $\mathrm{OR}=1.527,95 \%$ $\mathrm{CI}=1.051-2.218, \mathrm{p}=0.0262 ; \mathrm{GG}$ vs $\mathrm{AG} / \mathrm{AA}$ adjusted $\mathrm{OR}=1.460,95 \% \mathrm{CI}=1.021-2.089$, $\mathrm{p}=0.0381$ ). By combining the analysis of the risk genotypes in the three SNPs, we found that individuals with 2-3 risk genotypes had a significantly increased risk of recurrent miscarriage compared with those with a $0-1$ risk genotype (adjusted $\mathrm{OR}=1.728,95 \%$ $\mathrm{CI}=1.112-2.683, \mathrm{p}=0.0149)$. This risk was more significant in subgroups of women less than 35-40 years of age and women with 2-3 miscarriages.

Conclusion: These results suggested that a specific SNP in the ANRIL gene may be associated with increased susceptibility to recurrent miscarriage in a southern Chinese population.

Keywords: recurrent miscarriage, lncRNA $A N R I L$, genetic susceptibility, polymorphism

\section{Introduction}

Recurrent miscarriage (RM) is defined as at least two consecutive miscarriages that occurred with the same husband before the 20 th week of gestation. ${ }^{1}$ Currently, the causes of recurrent miscarriage remain unknown. Accumulating evidence has suggested that immunological dysfunction, endocrine disorders, thrombophilia, abnormal placental function, parental chromosomal abnormalities and unhealthy life patterns are risk factors for recurrent miscarriage. ${ }^{2-6}$ In recent years, research has found that genetic polymorphisms play an important role in the pathogenesis of miscarriage, and an increasing number of genetic polymorphisms are thought to be related to the occurrence of miscarriage. ${ }^{6-9}$ Previous research has shown that there is an association between recurrent miscarriage and an increased risk of
Correspondence: Xiaoqiong Gu Department of Clinical Biological Resource Bank, Guangzhou Institute of Pediatrics, Guangzhou Women and Children's Medical Center, Guangzhou Medical University, 9 Jinsui Road, Guangzhou, 510623, Guangdong, People's Republic of China

Tel/Fax +86-20-3807656l

Email guxiaoqiong@gwcmc.org 
cardiovascular disease in women later in life. ${ }^{10}$ In addition, some cardiovascular disease-related genes have been found to be risk factors for miscarriage, ${ }^{11-14}$ such as plasminogen activator inhibitor-1 (PAI-1), angiotensin I-converting enzyme (ACE), methylenetetrahydrofolate reductase (MTHFR) and apolipoprotein E (Apo E). ${ }^{15-19}$

Long noncoding RNA $A N R I L$ is a novel large antisense noncoding RNA that was first identified within the 403-kb germline deletion with a history of melanoma and neural system tumors in a French family. ${ }^{20}$ Recent evidence has suggested that numerous polymorphisms located in the ANRIL locus are associated with increased susceptibility to multiple diseases, such as cancers and cardiovascular disease. ${ }^{21}$ For instance, ANRIL gene polymorphisms contribute to the risk of ischemic stroke and increased risk of coronary artery disease, ${ }^{22,23}$ and ANRIL gene polymorphisms are significantly associated with breast cancer, glioma, endometriosis, melanoma and diabetes. ${ }^{24-27}$ In addition, endometriosis, cardiovascular disease, diabetes and breast cancer are also high-risk factors for miscarriage. However, few studies have investigated whether $A N R I L$ gene polymorphisms are associated with recurrent miscarriage. Therefore, we investigated whether ANRIL polymorphisms are related to recurrent miscarriage susceptibility. In the present case-control study, we investigated the association between ANRIL polymorphisms (rs2151280, rs1063192 and rs564398) and recurrent miscarriage susceptibility with 610 cases and 819 controls in a southern Chinese population.

\section{Materials and Methods Study Subjects}

According to the Declaration of Helsinki, the study was supported by the Ethics Committee of the Guangzhou Women and Children's Medical Center, and all participants signed an informed consent form (2018022202). Between June 2017 and June 2019, this study recruited 610 patients who had recurrent miscarriage, which was defined as two or more consecutive pregnancy losses before 20 weeks of gestation. The exclusion criteria were as follows: history of abnormal uterine anatomy; metabolic disorders; autoimmune conditions; arterial or venous thrombosis; liver or kidney dysfunction; and uterine abnormalities. The controls included 819 healthy controls who had at least two normal pregnancies and did not have a history of miscarriage or premature birth, and the healthy controls were age-matched to the case. Blood samples
(2 $\mathrm{mL})$ from each participant were collected for genetic analysis.

\section{DNA Extraction and SNP Genotyping}

Total genomic DNA from $200-\mu \mathrm{L}$ venous blood samples (collected from participants) was isolated using the TIANamp Blood DNA Kit (Tiangen, Beijing, China) following the manufacturer's instructions. Three SNP genotyping probes for the ANRIL gene (rs2151280, rs1063192 and rs564398) were purchased from ABI (Applied Biosystems, CA, USA), and all SNP genotyping was performed in a 384-well plate according to the TaqMan realtime polymerase chain reaction protocol on an $\mathrm{ABI} Q 6$ instrument (QuantStudio ${ }^{\mathrm{TM}} 6$ Flex Real-Time PCR System, Thermo Fisher Scientific, CA, USA). We have previously reported the details for this method. ${ }^{28,29}$

\section{Statistical Analysis}

Hardy-Weinberg equilibrium (HWE) was tested by the goodness-of-fit $\chi^{2}$ test for the control group. The allele and genotype frequencies (between recurrent miscarriage patients and healthy controls) were evaluated by the twosided chi-square test. The $95 \%$ confidence interval (CI) and odds ratio (OR) were used to assess the association between ANRIL gene polymorphisms and susceptibility to recurrent miscarriage. ORs and 95\% CIs were calculated by unconditional logistic regression analyses. Furthermore, the adjusted OR and corresponding 95\% CI were calculated to adjust for age through unconditional multiple logistic regression. A stratified analysis was performed for the age and number of miscarriages. All statistical tests consisted of bilateral analyses. SAS software (version 9.4; SAS Institute, Cary, NC, USA) was used to perform all statistical analyses. P-values less than 0.05 were considered statistically significant.

\section{Results}

\section{Population Characteristics}

In total, we enrolled 610 patients with recurrent miscarriage (20 to 46 years old) and 819 healthy controls (20 to 49 years old) (Table 1). There were no significant differences between recurrent miscarriage patients and agerelated controls $(32.43 \pm 5.41$ vs $32.81 \pm 5.08$ years, $\mathrm{p}=0.1796$ ). In addition, approximately $59.18 \%$ of patients with recurrent miscarriage experienced two or three miscarriages, and more than $40.82 \%$ of patients experienced four or more miscarriages in this study. 
Table I Frequency Distribution of Selected Characteristics in Recurrent Miscarriage and Controls

\begin{tabular}{|l|c|c|c|c|c|}
\hline \multirow{2}{*}{ Variables } & \multicolumn{2}{|c|}{$\begin{array}{c}\text { Cases } \\
(\mathbf{n = 6 1 0 )}\end{array}$} & \multicolumn{2}{c|}{$\begin{array}{c}\text { Controls } \\
(\mathbf{n = 8 1 9 )}\end{array}$} & \multirow{2}{*}{$\mathbf{P}^{\mathbf{a}}$} \\
\cline { 2 - 5 } & No. & $\%$ & No. & $\%$ & \\
\hline Age range, year & $20-46$ & & $20-49$ & & 0.1796 \\
\hline Mean \pm SD & \multicolumn{2}{|c|}{$32.43 \pm 5.41$} & \multicolumn{2}{|c|}{$32.81 \pm 5.08$} & \\
\hline$<35$ & 403 & 66.07 & 532 & 64.96 & \\
$35-40$ & 150 & 24.59 & 217 & 26.5 & \\
$>40$ & 57 & 9.34 & 70 & 8.55 & \\
\hline No. of miscarriages/\% & & & & & \\
\hline $2-3$ & 361 & 59.18 & & & \\
$\geq 4$ & 249 & 40.82 & & & \\
\hline
\end{tabular}

Note: ${ }^{\text {a Bilateral }} \chi^{2}$ test for distributions between recurrent miscarriage patients and controls.

\section{Association Between ANRIL Gene Polymorphisms and Recurrent Miscarriage Susceptibility}

We performed a goodness-of-fit $\chi^{2}$ test to test whether the genotype frequency of the distributed SNPs deviated from the expected pattern (Table 2). The genotype distribution of all SNPs was consistent with the HWE in the control. All $\mathrm{p}$-values were higher than $0.05(\mathrm{p}=0.319$ for $\mathrm{rs} 2151280, \mathrm{p}=0.119$ for $\mathrm{rs} 564398$ and $\mathrm{p}=0.85$ for rs1063192), indicating that all analyzed SNPs were consistent with HWE in the control group.

The single locus analysis suggested that two ANRIL gene SNPs modified recurrent miscarriage susceptibility. The rs2151280 GG genotype of the ANRIL gene showed increased recurrent miscarriage susceptibility (GG vs AA: adjusted $\mathrm{OR}=1.527,95 \% \quad \mathrm{CI}=1.051-2.218$, $\mathrm{p}=0.0262 ; \mathrm{GG}$ vs $\mathrm{AG} / \mathrm{AA}$ adjusted $\mathrm{OR}=1.460,95 \%$ $\mathrm{CI}=1.021-2.089, \mathrm{p}=0.0381$ ). There was a negative association of the rs1063192 variant allele of the ANRIL gene with recurrent miscarriage susceptibility. By combining the analyses of the risk genotypes in the three SNPs, we found that individuals with 2-3 risk genotypes had a significantly increased risk of recurrent miscarriage compared with those with $0-1$ risk genotypes (adjusted $\mathrm{OR}=1.728, \quad 95 \% \quad \mathrm{CI}=1.112-2.683$, $\mathrm{p}=0.0149$ ).

\section{Stratified Analysis of Selected Polymorphisms and Recurrent Miscarriage Susceptibility}

We further explored the association between three selected SNPs of the ANRIL gene and the risk of recurrent miscarriage susceptibility by stratifying age and the number of miscarriages (Table 3). By combining all risk genotypes, we found that carrying 2-3 risk genotypes had a higher risk in women less than 35-40 years of age $(\mathrm{OR}=2.903$, $95 \% \mathrm{CI}=1.198-7.033, \mathrm{p}=0.0183)$ and in women with $2-3$ miscarriages (adjusted $\mathrm{OR}=1.900,95 \% \mathrm{CI}=1.155-3.126$, $\mathrm{p}=0.0115$ ) compared to women carrying $0-1$ risk genotypes. However, this important finding needs to be further validated in studies with large sample sizes.

\section{Discussion}

Genetic factors play important roles in the pathogenesis of miscarriage. Polymorphism in many genes is thought to be related to miscarriage. In the present case-control study, we investigated the associations between ANRIL gene polymorphisms (rs2151280, rs564398 and rs1063192) and recurrent miscarriage susceptibility in a southern Chinese population. Among the three SNPs, we found that the rs2151280 GG allele was associated with an increased risk of recurrent miscarriage. However, the rs1063192 and rs564398 alleles were not related to recurrent miscarriage susceptibility.

LncRNA gene polymorphisms are associated with susceptibility to abortion. Studies have found that polymorphisms in some genes that regulate cell invasion and migration are related to susceptibility to abortion. ${ }^{30-32}$ Our previous research found that polymorphism in the IncRNA CCAT2 rs6983267 gene, which functions in regulating cell invasion and migration, is related to susceptibility to abortion (248 patients and 392 controls). ${ }^{33}$ Then, we tried to verify the results in a larger-sample population by assessing other functionally similar genes. Similarly, we found that IncRNA HULC polymorphisms that specifically regulate cell invasion and migration are related to susceptibility to miscarriage, and the result suggests that the rs $7770772 \mathrm{GC} /$ CC alleles, rs $1041279 \mathrm{GG}$ allele and rs17144343 GA/AA allele of the $H U L C$ gene are associated with decreased susceptibility to recurrent miscarriage. ${ }^{34}$ We further explored the relationship between other functional 
Table 2 Genotype and Allele Frequencies of ANRIL in RM Patients and Controls

\begin{tabular}{|c|c|c|c|c|c|c|c|}
\hline \multirow[t]{2}{*}{ Genotype/Allele } & RM & Controls & \multirow[t]{2}{*}{$P$-value ${ }^{a}$} & \multirow[t]{2}{*}{ OR $(95 \% \mathrm{Cl})$} & \multirow[t]{2}{*}{$P$-value } & \multirow[t]{2}{*}{ Adjusted OR (95\% Cl) } & \multirow[t]{2}{*}{$P$-value } \\
\hline & $(\mathbf{N}=6 \mid 0)$ & $(N=819)$ & & & & & \\
\hline \multicolumn{8}{|c|}{ ANRIL/rs2 I I I $280 \mathrm{~A}>\mathrm{G}(\mathrm{HWE}=0.319)$} \\
\hline AA & $278(45.57)$ & $402(49.08)$ & 0.0933 & I & I & I & l \\
\hline AG & $264(43.28)$ & $352(42.98)$ & l & $1.085(0.869-1.353)$ & 0.4717 & $1.098(0.880-1.37 I)$ & 0.4070 \\
\hline GG & $68(11.15)$ & $65(7.94)$ & l & $1.513(1.042-2.196)$ & 0.0295 & $1.527(1.05 \mid-2.218)$ & 0.0262 \\
\hline Dominant & $332(54.43)$ & $417(50.92)$ & 0.1886 & $I .15 I(0.933-I .42 I)$ & 0.1888 & $1.165(0.944-1.438)$ & 0.1548 \\
\hline Recessive & $542(88.85)$ & $754(92.06)$ & 0.0398 & $1.455(1.018-2.08 I)$ & 0.0396 & $1.460(1.021-2.089)$ & 0.0381 \\
\hline \multicolumn{8}{|c|}{ ANRIL/rs564398 T >C (HWE = 0.119) } \\
\hline TT & $479(78.52)$ & 642(78.39) & 0.8892 & I & l & 1 & l \\
\hline TC & $117(19.18)$ & $161(19.66)$ & l & $0.974(0.747-I .27 I)$ & 0.8460 & $0.973(0.746-1.270)$ & 0.8404 \\
\hline $\mathrm{CC}$ & $14(2.30)$ & $16(1.95)$ & l & $1.173(0.567-2.426)$ & 0.6675 & $1.217(0.586-2.525)$ & 0.5982 \\
\hline Dominant & $|3|(2 \mid .48)$ & $\mid 77(2|.6|)$ & 0.9506 & $0.992(0.769-1.280)$ & 0.9506 & $0.994(0.770-1.284)$ & 0.9659 \\
\hline Recessive & $596(97.70)$ & $803(98.05)$ & 0.6571 & I.179(0.57I-2.434) & 0.6564 & $1.224(0.591-2.534)$ & 0.5870 \\
\hline \multicolumn{8}{|c|}{ ANRIL/rsI063I92 A > G $(\mathrm{HWE}=0.85)$} \\
\hline AA & $427(70.00)$ & $553(67.52)$ & 0.4739 & 1 & l & 1 & l \\
\hline AG & $168(27.54)$ & $239(29.18)$ & I & $0.910(0.720-1.151)$ & 0.4320 & $0.909(0.719-1.149)$ & $0.424 I$ \\
\hline GG & $15(2.46)$ & $27(3.30)$ & l & $0.719(0.378-1.370)$ & 0.3161 & $0.729(0.383-1.389)$ & 0.3366 \\
\hline Dominant & $183(30.00)$ & $266(32.48)$ & 0.3175 & $0.891(0.710-1.118)$ & 0.3182 & $0.891(0.710-1.117)$ & 0.3170 \\
\hline Recessive & $595(97.54)$ & $792(96.70)$ & 0.3496 & $0.740(0.390-1.403)$ & 0.3554 & $0.750(0.395-1.423)$ & 0.3780 \\
\hline \multicolumn{8}{|c|}{ Combined risk-effect of genotypes * } \\
\hline $0-1$ & $560(91.80)$ & $780(95.24)$ & 0.0083 & $\mathbf{I}$ & I & $\mathbf{I}$ & I \\
\hline $2-3$ & $50(8.20)$ & $39(4.76)$ & & $1.7 \mid 2(1.103-2.657)$ & 0.0165 & $1.728(1.1 \mid 2-2.683)$ & 0.0149 \\
\hline
\end{tabular}

Notes: *The risk genotypes used for the calculation were as follows: rs $2151280 \mathrm{GG}+$ rs $564398 \mathrm{CC}+$ rs I063। 92 AA. ${ }^{\mathrm{a}} \chi^{2}$ test for genotype distributions between recurrent miscarriage patients and controls. ${ }^{b}$ Adjusted for age. Statistically significant values are shown in bold $(P<0.05)$.

Abbreviations: OR, odds ratio; HWE, Hardy-Weinberg equation; RM, recurrent miscarriage.

IncRNA genes and susceptibility to abortion. Studies have found that polymorphisms in some genes that play an important role in cardiovascular diseases are related to susceptibility to miscarriage. ${ }^{11-14}$ Our previous research also found that lncRNA MALAT1, which plays an important role in cardiovascular diseases, is related to susceptibility to miscarriage (248 patients and 392 controls). ${ }^{35}$ Similarly, we used a relatively large sample size to verify this result. Therefore, in this study, with other functionally similar genes, we explored the relationship between polymorphism in the ANRIL gene, which plays an important role in cardiovascular disease, and susceptibility to miscarriage. We found that the rs $2151280 \mathrm{GG}$ allele was associated with an increased risk of recurrent miscarriage. Studies have shown that both ANRIL and HULC are involved in regulating cell motility functions. ${ }^{36-39}$ Additionally, studies have found that the expression levels of $A N R I L$ and $H U L C$ are abnormal in patients with osteosarcoma, multiple sclerosis and breast cancer. ${ }^{40-42}$ However, research has shown that
ANRIL plays a more important role in cardiovascular disease. ANRIL gene polymorphisms contribute to the risk of ischemic stroke and increased risk of coronary artery disease. $^{22,23}$ In this research, we focus on highlighting some genes related to cardiovascular disease as risk factors for miscarriage and provide new perspectives for the study of genetic susceptibility to recurrent miscarriage.

ANRIL is located on the chromosome 9p21 locus and belongs to the long noncoding RNA group. ANRIL is considered to be a molecular scaffold for chromatin-modifying complexes, and it can control gene expression by modifying histone tails. ${ }^{43}$ Recently, accumulative evidence has suggested that ANRIL gene polymorphisms are associated with a variety of diseases, especially cardiovascular diseases, hypertension, endometriosis, breast cancer and diabetes. ${ }^{24,25,44-46}$ Moreover, cardiovascular diseases, hypertension, endometriosis, breast cancer and diabetes are also high-risk factors for miscarriage. ${ }^{12,47-49}$ Thus, the ANRIL gene polymorphism may be related to the onset of miscarriage. To the best of our 
Table 3 Stratification Analysis for Associations Between ANRIL Polymorphism and Recurrent Miscarriage Risk in a South Chinese Population

\begin{tabular}{|c|c|c|c|c|c|c|c|}
\hline \multirow[t]{3}{*}{ Variable } & \multirow{2}{*}{\multicolumn{2}{|c|}{$\begin{array}{c}\text { Combined Effect of Risk } \\
\text { Genotype }\end{array}$}} & \multirow[t]{3}{*}{$\mathbf{P}$} & \multirow[t]{3}{*}{ OR $(95 \% \mathrm{Cl})$} & \multirow[t]{3}{*}{$\mathbf{P}$} & \multirow[t]{3}{*}{ Adjust OR } & \multirow[t]{3}{*}{$\mathbf{P}^{\mathbf{a}}$} \\
\hline & & & & & & & \\
\hline & $0-1$ & $2-3$ & & & & & \\
\hline \multicolumn{8}{|l|}{ Age } \\
\hline$<35$ & $374 / 507$ & $29 / 25$ & 0.1070 & $1.573(0.906-2.729)$ & 0.1076 & I & I \\
\hline $35-40$ & $135 / 209$ & $15 / 8$ & 0.0151 & $2.903(1.198-7.033)$ & 0.0183 & I & l \\
\hline$>40$ & $51 / 64$ & $6 / 6$ & 0.7086 & $1.255(0.382-4.124)$ & 0.7084 & I & I \\
\hline \multicolumn{8}{|l|}{ No. of miscarriage/\% } \\
\hline $2-3$ & $331 / 780$ & $30 / 39$ & 0.0200 & $1.813(1.107-2.968)$ & 0.0180 & $1.900(1.155-3.126)$ & 0.0115 \\
\hline $4 \geq$ & $229 / 780$ & $20 / 39$ & 0.0576 & $1.747(0.999-3.054)$ & 0.0504 & I.727 (0.986-3.025) & 0.0561 \\
\hline
\end{tabular}

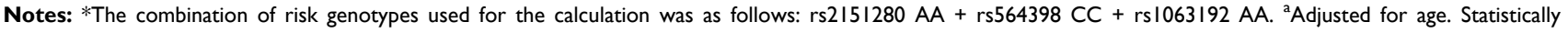
significant values are shown in bold $(P<0.05)$.

Abbreviations: OR, odds ratio; HWE, Hardy-Weinberg equation; RM, recurrent miscarriage.

knowledge, this study was the first to investigate the association between ANRIL gene polymorphisms (rs2151280, rs564398 and rs1063192) and susceptibility to recurrent miscarriage in a southern Chinese population. Pasmant et al found that an ANRIL gene polymorphism (rs2151280) is significantly associated with the number of plexiform neurofibromas in neurofibromatosis type 1 patients. ${ }^{50}$ Poi et al found that the ANRIL rs2151280 polymorphism is associated with worse progression-free survival in patients with multiple myeloma. ${ }^{51}$ The present study found that the rs 2151280 polymorphism in the ANRIL gene T allele was associated with an increased risk of recurrent miscarriage, which may be related to the regulation of the inflammatory response by the ANRIL gene. ${ }^{52}$ Wang et al found that the ANRIL rs 564398 polymorphism is associated with an increased risk of HBV-related gestational diabetes mellitus in a Chinese population. ${ }^{53}$ Other studies have confirmed that the ANRIL rs564398 variant is significantly associated with myocardial infarction after multivariate adjustments for coronary artery disease. ${ }^{54}$ However, the present study found that the ANRIL rs564398 variant allele was not related to susceptibility to recurrent miscarriage. Because there are differences in susceptibility genes between different ethnic groups, the results of genetic susceptibility need to be verified in different populations. Deng et al found that the ANRIL rs2151280 variant genotype may increase susceptibility to glioma in a Chinese Han population. ${ }^{55}$ Similarly, a study in an Italian population found that ANRIL rs2151280 polymorphism is associated with optic glioma development. ${ }^{56}$ Research has shown that the rs 1063192 polymorphism is related to genetic risk factors for normal-tension glaucoma. ${ }^{57,58} \mathrm{Hu}$ et al found that the ANRIL rs1063192 polymorphism is significantly associated with a decreased risk of glaucoma. ${ }^{59}$ Moreover, Li et al confirmed that the rs1063192 variant is significantly associated with esophageal squamous cell carcinoma. ${ }^{60}$ In contrast, Chen et al found that the rs3217986 polymorphism is not associated with the risk of intracranial aneurysm in a Chinese population. ${ }^{61}$ Similarly, the present study demonstrated that there was a negative association of the ANRIL rs1063192 variant allele with recurrent miscarriage susceptibility. The above results suggest that ANRIL gene polymorphisms play different roles in various diseases. Our results need to be verified in populations of different genetic backgrounds.

Research has shown that women who have experienced recurrent miscarriage have a higher risk of miscarriages during the next pregnancy than those who have given birth successfully. ${ }^{62}$ Many studies have shown that advanced age is a risk factor for miscarriage, and women over 40 years old are five times more likely to have miscarriages than women 31 to 35 years old. ${ }^{63,64}$ High maternal age is an important risk factor for spontaneous miscarriage. The risk of spontaneous miscarriage in women aged 20-24 years is $8.9 \%$, compared with $74.7 \%$ for women aged more than 40 years. $^{64}$ By combining all risk genotypes, the present study demonstrated that carrying 2-3 risk genotypes had a higher risk in women less than 35-40 years of age and in women with 2-3 miscarriages compared to women carrying 0-1 risk genotypes. These results require a larger sample study for verification, and the molecular mechanism of these functions deserves further exploration. 
This case-control study is the first to assess the association between ANRIL gene polymorphism and susceptibility to recurrent miscarriage. Some limitations in our research should be addressed. First, only three SNPs (rs2151280, rs564398 and rs1063192) were investigated in our study, and more SNPs should be included in future studies. Second, our sample size was not large enough, resulting in limited statistical power. Future research will require a larger sample size to validate the association of the ANRIL gene polymorphism with recurrent miscarriage susceptibility in a southern Chinese population. Third, we only studied the relationship between the ANRIL gene polymorphism and susceptibility to recurrent miscarriage, and we did not detect ANRIL gene expression in patients.

In conclusion, this case-control study confirmed that the ANRIL gene rs2151280 GG genotype is associated with increased susceptibility to recurrent miscarriage. These results increase our understanding of the function of this gene in recurrent miscarriage and provide valuable insights into its role in disease pathogenesis. However, larger sample sizes and additional experiments should be performed to confirm the role of the ANRIL polymorphism in recurrent miscarriage susceptibility.

\section{Data Sharing Statement}

Please contact the author for data requests.

\section{Ethical Approval}

The study was supported by the Ethics Committee of the Guangzhou Women and Children's Medical Center, and all participants signed informed consent forms (2018022202).

\section{Acknowledgments}

We would like to thank the Clinical Biological Resource Bank of Guangzhou Women and Children's Medical Center for providing all the clinical samples.

\section{Author Contributions}

All authors contributed significantly to this work. All authors made substantial contributions to the conception and design of the study as well as the acquisition, analysis and interpretation of data. All authors participated in drafting the article or revising it critically for important intellectual content, and all authors agreed to submit the manuscript to the current journal. All authors gave final approval of the version to be published and agreed to be accountable for all aspects of the work.

\section{Funding}

This study was funded by the Guangdong Provincial Science and Technology Plan (China, 2017A030223003), the Guangdong Natural Science Foundation (China, 2019A1515012061,202102010197), Guangzhou Science and Technology Program Key Projects (China, 201904010486), Guangzhou Health Commission(China, 20211A011034), and the Guangzhou Institute of Pediatrics/Guangzhou Women and Children's Medical Center Fund (China, GCP-2019-003, GCP-2019-006 and YIP-2019-050).

\section{Disclosure}

The authors report no conflicts of interest in this work.

\section{References}

1. Diejomaoh MF. Recurrent spontaneous miscarriage is still a challenging diagnostic and therapeutic quagmire. Med Princ Pract. 2015;24(Suppl 1):38-55. doi:10.1159/000365973

2. Kuon RJ, Strowitzki T, Sohn C, Daniel V, Toth B. Immune profiling in patients with recurrent miscarriage. $J$ Reprod Immunol. 2015;108:136-141. doi:10.1016/j.jri.2015.01.007

3. Kaur R, Gupta K. Endocrine dysfunction and recurrent spontaneous abortion: an overview. Int J Appl Basic Med Res. 2016;6:79-83. doi:10.4103/2229-516X.179024

4. Hyde KJ, Schust DJ. Genetic considerations in recurrent pregnancy loss. Cold Spring Harb Perspect Med. 2015;5:a023119. doi:10.1101/ cshperspect.a023119

5. Davenport WB, Kutteh WH. Inherited thrombophilias and adverse pregnancy outcomes: a review of screening patterns and recommendations. Obstet Gynecol Clin North Am. 2014;41(1): 133-144. doi:10.1016/j.ogc.2013.10.005

6. Shi X, Xie X, Jia Y, Li S. Maternal genetic polymorphisms and unexplained recurrent miscarriage: a systematic review and meta-analysis. Clin Genet. 2017;91:265-284. doi:10.1111/cge.12910

7. Su MT, Lin SH, Chen YC. Genetic association studies of angiogenesisand vasoconstriction-related genes in women with recurrent pregnancy loss: a systematic review and meta-analysis. Hum Reprod Update. 2011;17:803-812. doi:10.1093/humupd/dmr027

8. Pereza N, Ostojic S, Kapovic M, Peterlin B. Systematic review and meta-analysis of genetic association studies in idiopathic recurrent spontaneous abortion. Fertil Steril. 2017;107:150-159 e2. doi:10. 1016/j.fertnstert.2016.10.007

9. Arias-Sosa LA, Acosta ID, Lucena-Quevedo E, Moreno-Ortiz H, Esteban-Perez C, Forero-Castro M. Genetic and epigenetic variations associated with idiopathic recurrent pregnancy loss. J Assist Reprod Genet. 2018;35:355-366. doi:10.1007/s10815-017-1108-y

10. Oliver-Williams CT, Heydon EE, Smith GC, Wood AM. Miscarriage and future maternal cardiovascular disease: a systematic review and meta-analysis. Heart. 2013;99:1636-1644. doi:10.1136/heartjnl-20 12-303237

11. Ozdemir O, Yenicesu GI, Silan F, et al. Recurrent pregnancy loss and its relation to combined parental thrombophilic gene mutations. Genet Test Mol Biomarkers. 2012;16(4):279-286. doi:10.1089/gtmb.2011.0191

12. El Achi H, Awwad J, Abou Daya S, Halabi S, Damianos S, Mahfouz R. The association between cardiovascular disease gene mutations and recurrent pregnancy loss in the Lebanese population. Mol Biol Rep. 2018;45(5):911-916. doi:10.1007/s11033-018-4237-1 
13. Lane DA, Grant PJ. Role of hemostatic gene polymorphisms in venous and arterial thrombotic disease. Blood. 2000;95 (5):1517-1532. doi:10.1182/blood.V95.5.1517.005k48_1517_1532

14. Gardemann A, Lohre J, Katz N, Tillmanns H, Hehrlein FW, Haberbosch W. The 4G4G genotype of the plasminogen activator inhibitor $4 \mathrm{G} / 5 \mathrm{G}$ gene polymorphism is associated with coronary atherosclerosis in patients at high risk for this disease. Thromb Haemost. 1999;82(09):1121-1126. doi:10.1055/s-0037-1614340

15. Li J, Chen Y, Wu H, Li L. Apolipoprotein E (Apo E) gene polymorphisms and recurrent pregnancy loss: a meta-analysis. $J$ Assist Reprod Genet. 2014;31(2):139-148. doi:10.1007/s10815-013-0128-5

16. Eichner JE, Dunn ST, Perveen G, Thompson DM, Stewart KE, Stroehla BC. Apolipoprotein E polymorphism and cardiovascular disease: a HuGE review. Am J Epidemiol. 2002;155:487-495. doi:10.1093/aje/ 155.6.487

17. Ciftdogan DY, Coskun S, Ulman C, Tikiz H. The factor V G1691A, factor V H1299R, prothrombin G20210A polymorphisms in children with family history of premature coronary artery disease. Coron Artery Dis. 2009;20:435-439. doi:10.1097/MCA.0b013e32832bdb8c

18. Varga EA, Sturm AC, Misita CP, Moll S. Cardiology patient pages. Homocysteine and MTHFR mutations: relation to thrombosis and coronary artery disease. Circulation. 2005;111(19):e289-93. doi:10. 1161/01.CIR.0000165142.37711.E7

19. Buchholz T, Lohse P, Rogenhofer N, Kosian E, Pihusch R, Thaler CJ. Polymorphisms in the ACE and PAI-1 genes are associated with recurrent spontaneous miscarriages. Hum Reprod. 2003;18:24 73-2477. doi:10.1093/humrep/deg474

20. Pasmant E, Laurendeau I, Heron D, Vidaud M, Vidaud D, Bieche I. Characterization of a germ-line deletion, including the entire INK4/ ARF locus, in a melanoma-neural system tumor family: identification of ANRIL, an antisense noncoding RNA whose expression coclusters with ARF. Cancer Res. 2007;67:3963-3969. doi:10.1158/0008-5472. CAN-06-2004

21. Aguilo F, Di Cecilia S, Walsh MJ. Long non-coding RNA ANRIL and polycomb in human cancers and cardiovascular disease. Curr Top Microbiol Immunol. 2016;394:29-39. doi:10.1007/82 2015455

22. Xu B, Fang Z, He S, Wang J, Yang X. ANRIL polymorphism rs4977574 is associated with increased risk of coronary artery disease in Asian populations: a meta-analysis of 12,005 subjects. Medicine. 2018;97(39):e12641. doi:10.1097/MD.0000000000012641

23. Yang J, Gu L, Guo X, et al. LncRNA ANRIL expression and ANRIL gene polymorphisms contribute to the risk of ischemic stroke in the Chinese Han Population. Cell Mol Neurobiol. 2018;38(6):1253-1269. doi:10.1007/s10571-018-0593-6

24. Nakaoka H, Gurumurthy A, Hayano T, et al. Allelic imbalance in regulation of ANRIL through chromatin interaction at 9p21 endometriosis risk locus. PLoS Genet. 2016;12:e1005893. doi:10.1371/journal.pgen. 1005893

25. Broadbent HM, Peden JF, Lorkowski S, et al. Susceptibility to coronary artery disease and diabetes is encoded by distinct, tightly linked SNPs in the ANRIL locus on chromosome 9p. Hum Mol Genet. 2008;17:806-814. doi:10.1093/hmg/ddm352

26. Cunnington MS, Santibanez Koref M, Mayosi BM, Burn J, Keavney B, Gibson G. Chromosome 9p21 SNPs associated with multiple disease phenotypes correlate with ANRIL expression. PLoS Genet. 2010;6(4): e1000899. doi:10.1371/journal.pgen.1000899

27. Khorshidi HR, Taheri M, Noroozi R, Sarrafzadeh S, Sayad A, Ghafouri-Fard S. ANRIL genetic variants in iranian breast cancer patients. Cell J. 2017;19:72-78. doi:10.22074/cellj.2017.4496

28. Fang Z, Che D, Qing S, et al. The lncRNA SOX2OT rs9839776 C >T polymorphism indicates recurrent miscarriage susceptibility in a Southern Chinese Population. Mediators Inflamm. 2019;20 19:9684703. doi:10.1155/2019/9684703
29. Che D, Fang Z, Pi L, et al. The SERPINA4 rs2070777 AA genotype is associated with an increased risk of recurrent miscarriage in a Southern Chinese Population. Int J Womens Health. 2021;13: 111-117. doi:10.2147/IJWH.S290009

30. Jeon YJ, Kim YR, Lee BE, et al. Genetic association of five plasminogen activator inhibitor-1 (PAI-1) polymorphisms and idiopathic recurrent pregnancy loss in Korean women. Thromb Haemost. 2013;110(10):742-750. doi:10.1160/TH13-03-0242

31. Ostojic S, Pereza N, Volk M, Kapovic M, Peterlin B. Genetic predisposition to idiopathic recurrent spontaneous abortion: contribution of genetic variations in IGF-2 and H19 imprinted genes. Am J Reprod Immunol. 2008;60:111-117. doi:10.1111/j.1600-0897.2008.00601.x

32. Tian FJ, Qin CM, Li XC, et al. Decreased stathmin-1 expression inhibits trophoblast proliferation and invasion and is associated with recurrent miscarriage. Am J Pathol. 2015;185:2709-2721. doi:10. 1016/j.ajpath.2015.06.010

33. Che D, Huang W, Fang Z, et al. The lncRNA CCAT2 rs6983267 $\mathrm{G}$ allele is associated with decreased susceptibility to recurrent miscarriage. J Cell Physiol. 2019;234:20577-20583.

34. Fang Z, Yang Y, Xu Y, et al. LncRNA HULC polymorphism is associated with recurrent spontaneous abortion susceptibility in the Southern Chinese Population. Front Genet. 2019;10:918. doi:10. 3389/fgene.2019.00918

35. Che D, Yang Y, Xu Y, et al. The lncRNA MALAT1 rs619586 $\mathrm{G}$ variant confers decreased susceptibility to recurrent miscarriage. Front Physiol. 2019;10:385. doi:10.3389/fphys.2019.00385

36. Wang CH, Li QY, Nie L, Ma J, Yao CJ, Chen FP. LncRNA ANRIL promotes cell proliferation, migration and invasion during acute myeloid leukemia pathogenesis via negatively regulating miR-34a. Int J Biochem Cell Biol. 2020;119:105666. doi:10.1016/j.biocel.2019.105666

37. Dong X, Jin Z, Chen Y, et al. Knockdown of long non-coding RNA ANRIL inhibits proliferation, migration, and invasion but promotes apoptosis of human glioma cells by upregulation of miR-34a. $J$ Cell Biochem. 2018;119:2708-2718. doi:10.1002/jcb.26437

38. Yan C, Wei S, Han D, et al. LncRNA HULC shRNA disinhibits miR-377-5p to suppress the growth and invasion of hepatocellular carcinoma in vitro and hepatocarcinogenesis in vivo. Ann Transl Med. 2020;8(20):1294. doi:10.21037/atm-20-5556

39. Feng H, Wei B, Zhang Y. Long non-coding RNA HULC promotes proliferation, migration and invasion of pancreatic cancer cells by down-regulating microRNA-15a. Int $J$ Biol Macromol. 2019;126:891-898. doi:10.1016/j.ijbiomac.2018.12.238

40. Ghafouri-Fard S, Shirvani-Farsani Z, Hussen BM, Taheri M. The critical roles of IncRNAs in the development of osteosarcoma. Biomed Pharmacother. 2021;135:111217. doi:10.1016/j.biopha.2021.111217

41. Fenoglio C, Oldoni E, Serpente M, et al. LncRNAs expression profile in peripheral blood mononuclear cells from multiple sclerosis patients. $\quad J$ Neuroimmunol. 2018;324:129-135. doi:10.1016/j. jneuroim.2018.08.008

42. Tuluhong D, Dunzhu W, Wang J, et al. Prognostic value of differentially expressed LncRNAs in triple-negative breast cancer: a systematic review and meta-analysis. Crit Rev Eukaryot Gene Expr. 2020;30:447-456. doi:10.1615/CritRevEukaryotGeneExpr.2020035836

43. Holdt LM, Teupser D. Long noncoding RNA ANRIL: lnc-ing genetic variation at the chromosome 9p21 locus to molecular mechanisms of atherosclerosis. Front Cardiovasc Med. 2018;5:145. doi:10.3389/ fcvm.2018.00145

44. Aloraifi F, McDevitt T, Martiniano R, et al. Detection of novel germline mutations for breast cancer in non-BRCA1/2 families. FEBS J. 2015;282:3424-3437. doi:10.1111/febs.13352

45. Kunnas T, Piesanen J, Nikkari ST. Association of a chromosome locus 9p21.3 CDKN2B-AS1 variant rs4977574 with hypertension: the TAMRISK Study. Genet Test Mol Biomarkers. 2018;22:327-330. doi: $10.1089 / \mathrm{gtmb} .2017 .0249$ 
46. Aarabi G, Zeller T, Seedorf H, et al. Genetic susceptibility contributing to periodontal and cardiovascular disease. $J$ Dent Res. 2017;96:610-617. doi:10.1177/0022034517699786

47. Kharazmi E, Fallah M, Luoto R. Miscarriage and risk of cardiovascular disease. Acta Obstet Gynecol Scand. 2010;89(2):284-288. doi:10.3109/00016340903380758

48. Abell SK, Nankervis A, Khan KS, Teede HJ. Type 1 and type 2 diabetes preconception and in pregnancy: health impacts, influence of obesity and lifestyle, and principles of management. Semin Reprod Med. 2016;34(02):110-120. doi:10.1055/s-00351571196

49. Kohl Schwartz AS, Wolfler MM, Mitter V, et al. Endometriosis, especially mild disease: a risk factor for miscarriages. Fertil Steril. 2017;108(5):806-814 e2. doi:10.1016/j. fertnstert.2017.08.025

50. Pasmant E, Sabbagh A, Masliah-Planchon J, et al. Role of noncoding RNA ANRIL in genesis of plexiform neurofibromas in neurofibromatosis type 1. J Natl Cancer Inst. 2011;103:1713-1722.

51. Poi MJ, Li J, Sborov DW, et al. Polymorphism in ANRIL is associated with relapse in patients with multiple myeloma after autologous stem cell transplant. Mol Carcinog. 2017;56:1722-1732. doi:10.1002/mc.22626

52. Feng L, Guo J, Ai F. Circulating long noncoding RNA ANRIL downregulation correlates with increased risk, higher disease severity and elevated pro-inflammatory cytokines in patients with acute ischemic stroke. J Clin Lab Anal. 2018;e22629. doi:10.1002/ jcla.22629

53. Wang S, Liu J, Wang Q, Du J, Wang B. The CDKN2A polymorphisms and the susceptibility of HBV-related gestational diabetes mellitus. J Clin Lab Anal. 2018;32(6):e22423.

54. AlRasheed MM, Hefnawy MM, Elsherif NN, et al. The role of CDKN2B in cardiovascular risk in ethnic Saudi Arabs: a validation study. Gene. 2018;673:206-210. doi:10.1016/j. gene.2018.06.024

55. Deng Y, Zhou L, Li N, et al. Impact of four lncRNA polymorphisms (rs2151280, rs7763881, rs1136410, and rs3787016) on glioma risk and prognosis: a case-control study. Mol Carcinog. 2019;58: 2218-2229. doi:10.1002/mc.23110
56. Tritto V, Ferrari L, Esposito S, et al. Non-coding RNA and tumor development in neurofibromatosis type 1: ANRIL Rs2151280 is associated with optic glioma development and a mild phenotype in neurofibromatosis type 1 patients. Genes. 2019;10(11):892. doi:10.3390/genes10110892

57. Burdon KP, Awadalla MS, Mitchell P, et al. DNA methylation at the 9p21 glaucoma susceptibility locus is associated with normal-tension glaucoma. Ophthalmic Genet. 2018;39(2):221-227. doi:10.1080/ 13816810.2017.1413659

58. Mabuchi F, Sakurada Y, Kashiwagi K, Yamagata Z, Iijima H, Tsukahara S. Association between genetic variants associated with vertical cup-to-disc ratio and phenotypic features of primary open-angle glaucoma. Ophthalmology. 2012;119(9):1819-1825. doi:10.1016/j.ophtha.2012.02.044

59. Hu Z, He C. CDKN2B gene rs1063192 polymorphism decreases the risk of glaucoma. Oncotarget. 2017;8(13):21167-21176. doi:10. 18632/oncotarget.15504

60. Li WQ, Pfeiffer RM, Hyland PL, et al. Genetic polymorphisms in the 9p21 region associated with risk of multiple cancers. Carcinogenesis. 2014;35:2698-2705. doi:10.1093/carcin/bgu203

61. Chen Y, Li G, Fan H, et al. CDKN2BAS gene polymorphisms and the risk of intracranial aneurysm in the Chinese population. $B M C$ Neurol. 2017;17:214. doi:10.1186/s12883-017-0986-z

62. Garrisi JG, Colls P, Ferry KM, Zheng X, Garrisi MG, Munne S. Effect of infertility, maternal age, and number of previous miscarriages on the outcome of preimplantation genetic diagnosis for idiopathic recurrent pregnancy loss. Fertil Steril. 2009;92(1):288-295. doi:10.1016/j.fertnstert.2008.05.056

63. van Kooij RJ, Habbema JD, Dorland M, Te Velde ER. Agedependent decrease in embryo implantation rate after in vitro fertilization. Fertil Steril. 1996;66:769-775. doi:10.1016/S00150282(16)58634-8

64. Nybo Andersen AM, Wohlfahrt J, Christens P, Olsen J, Melbye M. Maternal age and fetal loss: population based register linkage study. BMJ. 2000;320:1708-1712. doi:10.1136/bmj.320.7251.1708
Journal of Inflammation Research

\section{Publish your work in this journal}

The Journal of Inflammation Research is an international, peerreviewed open-access journal that welcomes laboratory and clinical findings on the molecular basis, cell biology and pharmacology of inflammation including original research, reviews, symposium reports, hypothesis formation and commentaries on: acute/chronic inflammation; mediators of inflammation; cellular processes; molecular mechanisms; pharmacology and novel anti-inflammatory drugs; clinical conditions involving inflammation. The manuscript management system is completely online and includes a very quick and fair peerreview system. Visit http://www.dovepress.com/testimonials.php to read real quotes from published authors. 